\title{
Rousseau Misantropo
}

\author{
ROUSSEAU MISANTHROPE
}

\section{Pedro Paulo Corôa ${ }^{1}$}

\begin{abstract}
RESUMO: O objetivo de nossa exposição é mostrar que, em sua Carta a d'Alembert, Rousseau retoma o debate clássico sobre a relação entre o teatro e a moral nas mesmas bases estabelecidas por Platão. Sendo assim, a disputa sobre o teatro tem, da parte de Rousseau, uma objetividade que náo encontramos no artigo de d'Alembert. Portanto, não se trata de uma diferença de opiniâo entre Rousseau e d'Alembert, mas da capacidade filosófica de bem compreender o que é próprio ao teatro e à moralidade.
\end{abstract}

PALAVRAS-CHAVE: Teatro. Filósofo. Ética. Poética.

\section{- I -}

O objetivo desta exposição é abordar duas questôes a mim sugeridas pela leitura da Carta a d'Alembert, publicada por Rousseau em 1758, contendo uma réplica ao artigo "Genève", escrito por D’Alembert para a Encyclopédie de outubro de 1757. A primeira dessas questôes - mais geral - é a que diz respeito ao lugar próprio do teatro, ou da arte como um todo, no conjunto da Filosofia enquanto sistema, inclusive a de Rousseau. A segunda questão, alinhada a esta, concerne ao modo como Rousseau analisa o personagem Alceste, de $O$ misantropo, de Molière, objetivando, por meio disso, confirmar sua concepção artística ao aplicá-la à comédia. Rousseau quer consolidar, tomando a inserção de Alceste na comédia, seu juízo acerca do verbete de d'Alembert, impulsionando, assim, a chamada "querela" sobre o teatro a que sua Carta, desde então, ficou associada.

Nossa intenção é mostrar que o texto escrito por Rousseau não faz, apenas, uma crítica ao teatro - em especial à comédia. Em primeiro lugar, porque o filósofo, nessa Carta, mantém o mesmo ponto de vista que regula

\footnotetext{
${ }^{1}$ Doutor em Filosofia pela USP, membro da Sociedade Kant Brasileira e do Grupo de Sustentação do GT "Rousseau e o Iluminismo" (ANPOF). Professor de Ética e Estética, no Programa de Mestrado em Filosofia, e de Epistemologia, no Programa de Doutorado de Ciências Sociais, ambos na Universidade Federal do Pará - UFPA. E-mail: pcoroa@ufpa.br
}

http://dx.doi.org/10.1590/S0101-31732015000400007 
todos os demais textos por ele concebidos, quando nos descreve o caráter negativo da relação entre ética e poética - contrariando a tese defendida pelo artigo de d'Alembert, na Enciclopédia. Em segundo lugar, como muitos reconhecem, ele nos expóe seu próprio perfil - tanto como moralista quanto como "misantropo" - e nos aponta, apesar das várias ambiguidades que o assunto suscita, um possível vínculo positivo do teatro com a moral, vínculo reconhecido por Rousseau no desenho da personalidade de Alceste, tal como o compóe o próprio Molière - que, aliás, o interpretou pessoalmente em cena (MOLIÈRE, 2000, p. 205).

Talvez a escolha de Rousseau por $O$ misantropo se deva ao fato de essa obra permitir uma abertura para, a um só tempo, recusar, ex principiis, o "conselho" dado aos genebrinos por d'Alembert, em seu artigo, e recuperar, graças à análise do caráter de Alceste, o antigo ideal grego da kalokagathia por meio do qual se concebe a reunião, livre, de dois fins que, embora estejam muito próximos em suas raízes subjetivas (ética e poética), são funcional e “objetivamente" falando distintos: afinal, cada um deles obedece a princípios que, per se, são independentes um do outro, não devendo, portanto, ser confundidos.

A passagem que nos dá essa chave de leitura e, com isso, modera a crítica de Rousseau - ao mesmo tempo, obviamente, em que a confirma - é a seguinte:

Em todas as outras peças de Molière, a personagem ridícula é sempre odiosa ou desprezível; nessa, embora Alceste tenha defeitos reais de que não há erro em rir, sentimos, contudo, no fundo do coração um respeito por ele de que não podemos nos defender. (ROUSSEAU, 2003, p. 88).

E, por conseguinte, fazendo referência ao modo - único - como deve um filósofo, desde Platão, abordar o elo capaz de unir, como quer d'Alembert, teatro e moral, Rousseau completa: "Nessa ocasiāo [em que emerge em nós o sentimento de respeito, ou seja, moral, pelo personagem], a força da virtude sobrepuja a arte do autor e honra seu caráter" (grifos nossos).

\section{- II -}

$\mathrm{Na}$ Carta a d'Alembert, Rousseau define dois momentos para estruturar sua exposiçáo que interessam à nossa. $\mathrm{O}$ primeiro, quando faz consideraçóes 
gerais sobre o teatro enquanto instituição, e o segundo, quando procura nos fazer reconhecer esses princípios gerais na tragédia e na comédia, principalmente aplicando o modo como define a natureza desta (comédia) ao "teatro cômico francês".

Percebe-se logo que Rousseau parece considerar a solução dada por d'Alembert demasiado rápida para um assunto tão complexo - além de muitíssimo sério. Ele escreve: "Quantas questôes por discutir na questão que V. Sa parece resolver!" Basicamente, a resolução, no artigo da Enciclopédia, é a suposiçáa - que está mais para uma prise en charge - de que o teatro pode ser útil à promoção dos bons costumes. Rousseau procura mostrar que existem inúmeras interrogaçôes as quais precisam ser respondidas antes que as conclusões a que chega d'Alembert possam ter algum valor de necessidade indo, assim, além da retórica e justificando-se efetivamente.

Rousseau condiciona o tratamento correto do tema a uma série contínua de questóes que ele deliberadamente interrompe, ao chegar à oitava delas. A nós interessa, sobretudo, as duas primeiras interrogaçôes, levantadas por Rousseau de modo a regular sua análise. São as seguintes: "Se os espetáculos são bons ou maus em si mesmos?" E: "Se podem aliar-se aos bons costumes?" (ROUSSEAU, 2003, p. 63). São essas duas questôes que consideramos aqui como de alcance geral, até porque elas nos permitem sintonizar a abordagem imprimida por Rousseau a toda tradição filosófico-literária, escapando, assim, de confundir o "inesperado" contraditório de Rousseau a seu amigo com uma mera alteração de humor associada à suspeita de que Voltaire fosse a eminência parda por trás do artigo de d'Alembert.

Rousseau, ao contrário do que se costuma pensar - e bem diferente do que reconhece, no texto de d'Alembert -, não está, apenas, emitindo sua opinião, ao tratar do assunto. Ele procura abordá-la impessoal e objetivamente. E é isso que nos revelam as duas primeiras interrogaçôes por ele propostas. Elas são clássicas, no sentido próprio do termo: afinal, todas teriam sido colocadas por Platão, por Aristóteles ou mesmo por Kant, em sua Crítica do Juizo. Elas têm a ver com a definiçáo precisa de cada um dos objetos de que se fala, de cada elemento envolvido na questão. É essa garantia de precisão no uso dos termos que levará, mais à frente, a que Rousseau quase inverta o sentido da expressão "misantropia” aplicada a Alceste por Molière.

Gostaríamos de chamar o testemunho ad hoc de Aristóteles, para a possível razão do mal-entendido que motiva o artigo de d'Alembert e que, para 
ser denunciado, exige de Rousseau um esforço - náo feito pelo enciclopedista - em determinar corretamente a função própria àquele que esteja situado na função de poeta e/ou de moralista. No Livro VI, Capítulo 4, de Ética a Nicômaco, Aristóteles classifica as coisas que envolvem o poietòn (poético) e as coisas que envolvem o praktón (ação moral) no rol do que devemos considerar como tendo uma natureza variável ou meramente possível (tou d'endekoménou), opondo ambas, com isso, à ciência (epistéme), que trata do invariável, ou daquilo que sempre é (aídia), pois “[...] existe necessariamente (ex anánkes onta)”. Mas, afirma ele: "Há uma diferença (éteron d'estin) entre produzir (poíesis) e agir (praxis)", de sorte a "[...] não se incluírem uma na outra".

No Capítulo 5, ao tratar da especificidade da ética, escreve Aristóteles: “A sabedoria prática (phrónesin) deve ser uma capacidade verdadeira e raciocinada (metà lógou alethê) de agir com respeito aos bens humanos (peri tà anthrópina agathà praktikén)". Dessa forma, Aristóteles ressalta uma coisa interessante para nossa compreensão da análise rousseauniana da arte: “[...] embora na arte (tékhnes) possa haver uma excelência (aretê)", nela “[...] é preferível quem erra voluntariamente (amartánon airetóteros), enquanto na sabedoria prática (perì phrónesin), assim como nas outras virtudes, é exatamente o contrário que acontece”, ou seja, é proibido errar - voluntariamente. Conclusão: “A sabedoria prática é uma virtude (areté) e não uma arte (tékhne)". Na verdade, arte e virtude apontam para fins diferentes. E, conforme destaca Rousseau, essa relação só é positiva quando "[...] a força da virtude sobrepuja a arte do autor".

Ora, não é a mesma preocupação de Aristóteles que comanda o texto de Rousseau? Preocupação que, antes de Aristóteles, ocupou Platão, no Livro $\mathrm{X}$ da República - livro mil vezes falsificado pela maioria de seus intérpretes. E a questão de Platão era, inquestionavelmente, a mesma de Rousseau: qual a importância do poeta para uma república (politeia), isto é, que contribuição a arte pode dar à moralidade dos costumes? Resposta de Platáo: Nenhuma!! Argumento: Em se tratando de legislação pública, a quem consultaríamos, a Homero ou a Licurgo, ao poeta (poietés) ou ao legislador (nomothétes)? Enfatiza Rousseau:

Só conheço três tipos de instrumentos com os quais podemos agir sobre os costumes dos povos; são eles: a força das leis, o império da opiniáo e a atração dos prazeres. Ora, as leis nâo tem nenhum acesso ao teatro, cujo menor constrangimento seria um sofrimento e não uma diversão. (ROUSSEAU, 2003, p. 70). 
É que o espetáculo público, como o define Rousseau, é um "entretenimento" e náo conserva em seu interior a seriedade e a gravidade dos assuntos morais. O que ele nos leva a pensar ou praticar não tem, em princípio, nenhuma ligação imediata com os temas ou com os conceitos morais. Por isso, Rousseau afirma:

Acreditamos reunir-nos (s’assembler) no espetáculo, e é ali que cada um se isola; é ali que vamos esquecer os amigos, os vizinhos, os próximos, para nos interessarmos por fábulas, para chorarmos as desgraças dos mortos ou rirmos dos vivos. (ROUSSEAU, 2003, p. 64-65).

Como se percebe, a função do teatro, independentemente de gênero - trágico ou cômico - é bem distinta àquela buscada em toda conformaçáo autenticamente moral da nossa existência. $\mathrm{O}$ moralista quer a unidade das vontades e, na arte, os homens têm, justamente, a oportunidade de multiplicar e dispersar as suas. A harmônica indiferença que nós nos representamos por meio do conceito moral de cidadania - e sem a qual o legislador não passaria de um déspota - é substituída, pois, pela liberação de qualquer compromisso comum, quando se trata da ação que leva à produção artística. $\mathrm{Na}$ arte, seria absurdo qualquer grau de nomophylaxia. Se, no teatro, como assinala Rousseau, nos juntamos para o isolamento, é porque isso faz parte da natureza dele (teatro) e nele se desfaz tudo que sugira a necessidade de vínculo, de relação. No teatro, a persona jamais se efetiva como personalidade pública. Devido a isso, o teatro é a mais "legítima" forma de idiossincrasia a que tem "direito" o homem.

A liberdade, no contexto estético, admitida e exigida para o artista, tem um sentido radicalmente "natural", ou seja, nela não devemos projetar absolutamente nada que envolva disposição social regulada, coletivamente convencionada, e que possamos reconhecer na ação humana pública. $\mathrm{Na}$ arte, o que move o homem - sua fonte afetiva - é a paixão, não a razão, de sorte que ela nos aproxima do que, em nós, mais corresponde ao estado de natureza. Em uma passagem da Carta, Rousseau escreve algo assim: "O amor do belo é um sentimento tão natural no coração humano quanto o amor de si”. Quer dizer, não é um sentimento objetivo e vinculante, como o sentimento moral, o qual supóe a razão. Ele é tão natural que, conforme salienta Rousseau, na sequência, “[...] ele não nasce de um arranjo de cena; o autor não o leva para lá, mas o encontra ali; e desse puro sentimento que ele favorece nascem as doces lágrimas que faz correr" (ROUSSEAU, 2003, p.71) 
Essa é a razão para a recusa de Rousseau em aceitar a tese de que, no teatro, as paixôes são purificadas - ou purgadas. Ele ironiza: "Será que para nos tornarmos temperantes e sábios precisamos começar por ser furiosos e loucos?" (ROUSSEAU, 2003, p. 68). O teatro, afirma ele, apenas acentua e renova todas as nossas paixôes, e o objetivo de toda a educação moral é o inverso: moderá-las. Por isso, "[...] o único instrumento capaz de purgá-las é a razão, e eu já disse que a razão não tem nenhum efeito no teatro”. E, novamente, a razão nos reúne todos em um todo - por isso ela, unicamente, é a base moralizante da ação. Em contrapartida, ainda que cultivada no interior da sociedade, a arte tem o poder de nos isolar, individualizando-nos na forma hermética do sentimento, inconfundível em cada um de nós. Em $A$ retórica das paixóes, Aristóteles nos fornece a fórmula geral para a precisa identificação do que ocorre em nós, quando sob o efeito da paixáo a que se liga o sentimento estético. Escreve ele o seguinte: "As paixôes [ta páthe] são todos aqueles sentimentos que, causando mudança [metabállontes] nas pessoas, fazem variar seus julgamentos [diaphérousi prós tàs kríseis]..." (ARISTÓTELES, 2003, p. 4-5). É que nossas paixôes são fontes inconciliáveis de percepçôes, o que advém de sua irredutibilidade a conceitos.

$\mathrm{Na}$ arte, como é o caso do teatro, cada um de nós tem o seu privilegium judicativo, isto é, goza de privacidade plena na avaliação e no veredito acerca dos espetáculos. É completamente natural, nesse caso, que nos dissociemos de todo e qualquer critério uniformizante, afinal, essa é a condição sem a qual o artista não prospera. Se o que rege o moralista é a representação da lei enquanto princípio inviolável, o princípio, para qualquer artista que saiba o que faz, é o do casuísmo, quer dizer, da exceção. O artista é o que faz a diferença, de onde vem o fato de sua obra só poder ser definida por uma palavra: singularidade! Enquanto ao moralista interessa a comunhão entre os homens, o artista é uma fonte inesgotável de excomunhão. Tudo o que ele faz, e por mais que faça, é único, inclassificável. Por isso, o artista não forma grupos, ele desfaz relaçóes, e suas obras são átomos absolutos. Daí se dizer que em toda reflexão artística o nosso pensamento, ou seja, o nosso modo de julgar é meramente estético, quer dizer, regido pelo sensível e sem nenhum valor abstrato, o que vem a ser: ele é imediato e intuitivo! No contexto artístico, pensar nunca é dar unidade a um múltiplo de coisas, como faz o cientista, ou unidade a um múltiplo de vontades, como faz, por exemplo, Rousseau, no Contrato social.

$\mathrm{Na}$ arte e, portanto, no juízo estético, o pensamento, cuja função básica é ir em busca das semelhanças, implode diante da obra. Porque o artista, para 
ser reconhecido como tal, invariavelmente, surpreende, pois o que ele faz nunca é ou será um caso a mais de uma representação universal, nunca é ou será parte de um todo. A surpresa que toda obra nos causa está em nunca podermos saber, antes que se manifeste, o que seu autor pretendia fazer, e o seu feito é um factum brutum diante do qual o pensamento, por si mesmo, nunca sabe, previamente, o que fazer. A arte é da ordem do imprevisível (tou d'endekoménou). Toda obra de arte é um puro dado para a nossa percepção, uma proto hylé desligada de qualquer vínculo formal objetivo, a matéria sem eidos. Por isso, podemos sustentar que a surpresa que a arte produz, pelo modo como nos afeta, nunca tem, como efeito em nós, outra coisa a não ser anular em nós a capacidade abstrata de pensar. Isto é, a arte torna, em nossa reflexão, todo conceito sem efeito, desfazendo em nós o justo equilíbrio, a phrónesis, como diziam os gregos, dando maior gravidade às nossas paixóes.

\section{- III -}

Feitas essas considerações, que chamamos de gerais, passemos, bem rapidamente, à questão da misantropia de Alceste, mas, também, a de Rousseau. A entrada no tema vou tirá-la de um trecho da Carta a Malesherbes. Nela, Rousseau escreve: "Nasci com um amor natural pela solidão que só fez aumentar conforme conhecia melhor os homens" (ROUSSEAU, 2005, p. 20). Esse é o mote para a análise do personagem Alceste, configurado, na pena de Molière, como o modelo de misantropo. Dirigindo-se a D'Alembert, enquanto comenta a peça, escreve Rousseau: "V. Sa não poderia negar-me duas coisas". E a primeira delas é: "Alceste nessa peça é um homem direito, sincero, estimável, um verdadeiro homem de bem" (ROUSSEAU, 2003, p. 86). Se assim é, como reitera Rousseau, na sequência, “[...] esse nome de 'Misantropo' não deve vingar, como se aquele que o tem fosse inimigo do gênero humano”.

Dessa maneira, Rousseau pergunta: "Que é entâo o Misantropo de Molière?” - E, completamos: à revelia do modo como o comediógrafo o póe em cena. Rousseau mesmo responde que o "misantropo" é, de fato, na ficção,

[u]m homem de bem que detesta os costumes de seu século e a maldade dos contemporâneos; que justamente porque ama seus semelhantes, odeia neles os males que se fazem uns aos outros e os vícios de que esses males são frutos. (ROUSSEAU, 2003, p. 86-87). 
Comparemos esse trecho das Cartas a d'Alembert com outro, das Cartas a Malesherbes, em que Rousseau alude a si mesmo:

\begin{abstract}
Amargurado pelas injustiças que experimentara ou testemunhara, afligido muitas vezes pela desordem para a qual o exemplo e a força das coisas me arrastavam, desprezei meu século [como Alceste] e meus contemporâneos [como Alceste], e sentindo que náo encontraria no meio deles uma situação que pudesse contentar meu coração, separei-o pouco a pouco da sociedade dos homens e criei uma outra em minha imaginação... (ROUSSEAU, 2005, p. 23-24).
\end{abstract}

São essas semelhanças que permitem a Rousseau criticar a comédia e, ao mesmo tempo, reconhecer os méritos de Molière. Reconhecer inclusive que os espetáculos podem até "encontrar alguma utilidade". Mas, assinala, "[...] o objetivo principal é agradar", divertir o povo. Ainda assim, seguindo a descrição do temperamento de Alceste, Rousseau conclui, como de si mesmo: "Não há homem de bem que não seja misantropo, neste sentido; ou melhor, os verdadeiros misantropos são aqueles que não pensam assim" (ROUSSEAU, 2003, p. 87).

É para satisfazer uma exigência - necessária e inevitável - da comédia, que Molière não só mistura e confunde o vício e a virtude. Ele troca-lhes os sinais no jogo que faz entre o destemperado Alceste e o, como o chama Rousseau, "fleumático" Philinte, que, não por acaso - em se tratando, obviamente, de uma comédia - é "le sage de la pièce". É assim que Rousseau descreve o calmo e sábio Philinte:

[...] uma dessas pessoas de bem da alta sociedade, cujas máximas são muito parecidas àquelas dos patifes (fripons), dessa gente tão doce, táo madura, que sempre acha que tudo vai bem, porque tem interesse em que elas não vão melhores; que está sempre contente com todos, porque não se preocupa com ninguém. (ROUSSEAU, 2003, p. 88).

Para Philinte - o sábio - parece fácil parecer um “filantropo", desde que não esqueçamos que se trata de uma comédia. Trocar os sinais naturais a cada coisa, confundir os modelos de caráter, "errar voluntariamente", como enfatiza Aristóteles, é isso que faz Molière. E é isso que faz de Molière, como admite Rousseau, um gênio da comédia. 
Enfim, a análise do misantropo, por Rousseau, é uma demonstração de como se poderia, com o auxílio da ficção, usar o teatro como meio alegórico de educação moral. Se, conforme assevera Rousseau, sua distinção entre os dois sentidos de misantropia

[...] forem justas, Molière compreendeu mal o Misantropo. Será que foi por erro? Não, sem dúvida. Mas eis como o desejo de fazer rir [que é a função própria do comediógrafo] às custas do personagem o forçou a degradá-la, contra a verdade do caráter. (ROUSSEAU, 2003, p. 90).

Para finalizar, cremos que dois traços são bem evidentes no texto da Carta a d'Alembert. O primeiro é a retomada da divergência - esmiuçada e previamente resolvida por Platão, em sua República - entre o moralista (e, diríamos: o Filósofo que, ao mesmo tempo, é o polités, o nomothétes, ou seja, o legislador) e o artista. O segundo é o que permite uma analogia com o Discurso sobre as ciências e as artes, sendo que, enquanto no Primeiro discurso a questáo era a tensa relação entre moral e ciência, agora, a mesma "maltratada" moral se vê na "má companhia" da poética. E, ainda assim, Rousseau poderia ter escrito: "Ce n'est point la poésie que je maltraite..."

CORÔA, Pedro Paulo. Rousseau misanthropel. Trans/Form/Ação, Marília, v. 38, p. 71-80, 2015. Edição Especial.

ABSTRACT: The purpose of this article is to show how Rousseau, in his Letter to D'Alembert, takes up the classic debate between theatre and morals on the same grounds established by Plato. In Rousseau's work, the debate about theatre has an objectivity that we do not find in D'Alembert's article. Therefore, what is involved is not a difference of opinion between Rousseau and D'Alembert, but a difference in the philosophical ability to fully understand what concerns both theatre and morality.

KEYWORDS: Theatre. Philosopher. Ethics. Poetics.

\section{REFERÊNCIAS}

ARISTÓTELES. Ética a Nicômaco. São Paulo: Nova Cultural, 1987. . Ethica Nicomachea. London: Oxford University Press, 1949.

2003. . Retórica das paixões. Tradução de Isis Borges Fonseca. São Paulo: Martins Fontes, 
CORÔA, P. P.

MOLIÈRE. Le misanthrope. Paris: Pocket, 2000.

ROUSSEAU, J.-J. Lettre à d'Alembert. Paris: Flammarion, 2003.

Carta a Malesherbes. In: Carta a Christophe de Beaumont e outros escritos sobre a religião e a moral. São Paulo: Estação Liberdade, 2005.

Recebido / Received: 15/04/2015

Aprovado / Approved: 24/06/2015 